\title{
Hasil Pengobatan Leukemia Mieloblastik Akut pada Anak
}

\author{
Hikari Ambara Sjakti, Djajadiman Gatot, Endang Windiastuti \\ Departemen Ilmu Kesehatan Anak Fakultas Kedokteran Universitas Indonesia/RS. Dr. Cipto \\ Mangunkusumo, Jakarta
}

\begin{abstract}
Latar belakang. Leukemia mieloblastik akut (LMA) merupakan penyakit keganasan yang sering ditemukan pada anak. Hasil pengobatan LMA di Departemen Ilmu Kesehatan Anak RSCM dalam satu dekade terakhir belum pernah dievaluasi.

Tujuan. Mengetahui karakteristik pasien LMA dan evaluasi hasil pengobatan serta protokol pengobatan. Metode. Penelitian deskritif dilakukan secara retrospektif terhadap rekam medis pasien LMA yang didiagnosis antara Januari 2007-Desember 2010 di Departemen Ilmu Kesehatan Anak RSCM. Karakteristik pasien secara klinis dan laboratoris dicatat, dan hasil pengobatan dianalisis. Estimasi kesintasan dihitung menggunakan metode Kaplan-Meier dengan bantuan program statistik.

Hasil. Selama rentang waktu penelitian didapatkan 93 pasien baru LMA. Overall survival (OS) adalah 46,2\% (95\% IK: 21,1\%;31,2\%) dan event-free survival (EFS) 6,5\% (95\% IK: 3,1\%;6,2\%). Angka loss to follow-up mencapai sepertiga jumlah pasien yang mempengaruhi hasil estimasi kesintasan (overall survival). Rendahnya EFS disebabkan oleh angka kematian yang tinggi mencapai 50 dari 93 pasien dan $62 \%$ di antaranya disebabkan oleh sepsis.

Kesimpulan. Keberhasilan pengobatan LMA masih sangat rendah dibandingkan laporan penelitian dari negara lain. Faktor yang paling berperan terhadap hal ini adalah kematian yang tinggi akibat infeksi berat atau sepsis. Komplikasi infeksi mungkin terjadi akibat toksisitas obat dan fasilitas perawatan untuk pasien LMA kurang memadai. Stratifikasi risiko pasien LMA dan evaluasi protokol kemoterapi yang diberikan serta penyediaan fasilitas perawatan yang baik akan memperbaiki hasil pengobatan LMA.
\end{abstract}

Sari Pediatri 2012;14(1):40-5.

Kata kunci: leukemia mieloblastik akut, luaran, anak

$\mathrm{L}$

eukemia akut merupakan keganasan tersering pada anak. ${ }^{1}$ Data registrasi kanker di Departemen Ilmu Kesehatan Anak FKUIRSCM mencatat kasus leukemia akut baru

\section{Alamat korespondensi:}

Dr. Hikari Ambara Sjakti, Sp.A(K), Divisi Hematologi-Onkologi Departemen Ilmu Kesehatan Anak, FKUI- RSCM, Jl. Diponegoro 71, Jakarta 10430. Telp. (021) 31901170, Fax.: (021) 3914145. sebanyak 426 dari 741 (57,5\%) kasus keganasan yang didiagnosis antara tahun 2007-2010. Dari semua kasus leukemia akut tersebut, leukemia mieloblastik akut (LMA) ditemukan 93 anak atau 21,8\%. ${ }^{2}$ Pengobatan yang diberikan pada kasus LMA umumnya adalah pemberian kemoterapi dan transplantasi sumsum tulang pada sebagian kasus yang terindikasi. Hambatan utama pengobatan LMA di institusi kami adalah kemampuan pasien memperoleh obat kemoterapi 
sangat rendah. Sejak mulai ada jaminan kesehatan bagi warga kurang mampu di Indonesia, hambatan tersebut sebagian dapat teratasi, sehingga diharapkan keberhasilan pengobatan LMA dapat ditingkatkan.

Hasil pengobatan LMA dalam beberapa dekade terakhir cenderung membaik yang ditunjukkan dengan angka remisi 70\%-80\%. ${ }^{3}$ Kesintasan cenderung meningkat dengan dilakukan transplantasi sumsum tulang. ${ }^{3,4}$ Sejauh ini belum ada laporan hasil pengobatan LMA dari Departemen Ilmu Kesehatan Anak RSCM. Penelitian dilakukan untuk mengetahui hasil pengobatan LMA dan mengumpulkan data awal untuk evaluasi protokol kemoterapi LMA.

\section{Metode}

Semua pasien berusia kurang dari 18 tahun yang didiagnosis LMA antara Januari 2007 sampai dengan Desember 2009 dan tercatat pada register kanker Departemen ilmu Kesehatan Anak FKUI-RSCM, diikutsertakan sebagai subyek penelitian. Pemeriksaan fisis, pemeriksaan darah tepi lengkap, aspirasi sumsum tulang dikerjakan pada semua pasien. Diagnosis dan klasifikasi LMA ditegakkan berdasarkan gambaran morfologi dari aspirasi sumsum tulang dan memakai klasifikasi French-American-British (FAB). Pemeriksaan imunofenotip hanya dikerjakan pada beberapa pasien karena keterbatasan biaya.

Protokol pengobatan yang digunakan adalah protokol kemoterapi LMA yang terdiri dari fase induksi, fase konsolidasi dan fase intensifikasi mengikuti protokol dari Emma Kinder Ziekenhuis/ Academisch Medisch Centrum (EKZ/AMC) 1987 yang dimodifikasi. Fase induksi menggunakan 1 blok protokol berupa metotreksat intratekal, sitosin arabinos, daunorubisin dan etoposid, diikuti fase konsolidasi selama 42 minggu dan 2 blok fase intensifikasi dengan sitosin arabinos dosis tinggi. Interval antara fase adalah 4 minggu (Tabel 1). Transplantasi sumsum tulang tidak termasuk dalam rencana pengobatan LMA karena fasilitas tersebut belum tersedia.

Karakteristik pasien yang dinilai adalah karakteristik klinis dan laboratoris, morfologi LMA berdasarkan klasifikasi FAB dan luaran pengobatan. Pasien dianggap remisi apabila hasil aspirasi sumsum tulang setelah menjalani 1 blok fase induksi, jumlah sel blas menunjukkan kurang dari 5\%. Apabila sel blas $>5 \%$ dianggap gagal remisi.
Estimasi kesintasan dihitung menggunakan analisis kesintasan Kaplan-Meier. Overall survival rate (OS) dihitung pada semua pasien dengan menggunakan waktu antara mulai didiagnosis sampai terjadi kematian. Event-free survival dihitung pada pasien yang menjalani kemoterapi dengan memakai waktu antara mulai didiagnosis sampai terdapat kejadian relaps, kematian atau loss to follow-up. Analisis statistik dilakukan menggunakan aplikasi SPSS versi 15.

\section{Hasil}

Sembilanpuluh tiga subyek dengan diagnosis LMA dilaporkan selama rentang waktu penelitian. Pasien LMA laki-laki lebih banyak ditemukan, perbandingan antara laki-laki dan perempuan 1,5:1. Dari semua pasien, dua pertiga di antaranya termasuk kelompok usia 1-10 tahun. Berdasarkan klasifikasi morfologi FAB, semua tipe LMA ditemukan (M1-M7), dan tipe terbanyak adalah LMA M1 hampir mencapai 50\% kasus (Tabel 2).

Tabel 1. Protokol kemoterapi LMA (EKZ/AML-87 dengan modifikasi) $)^{2}$

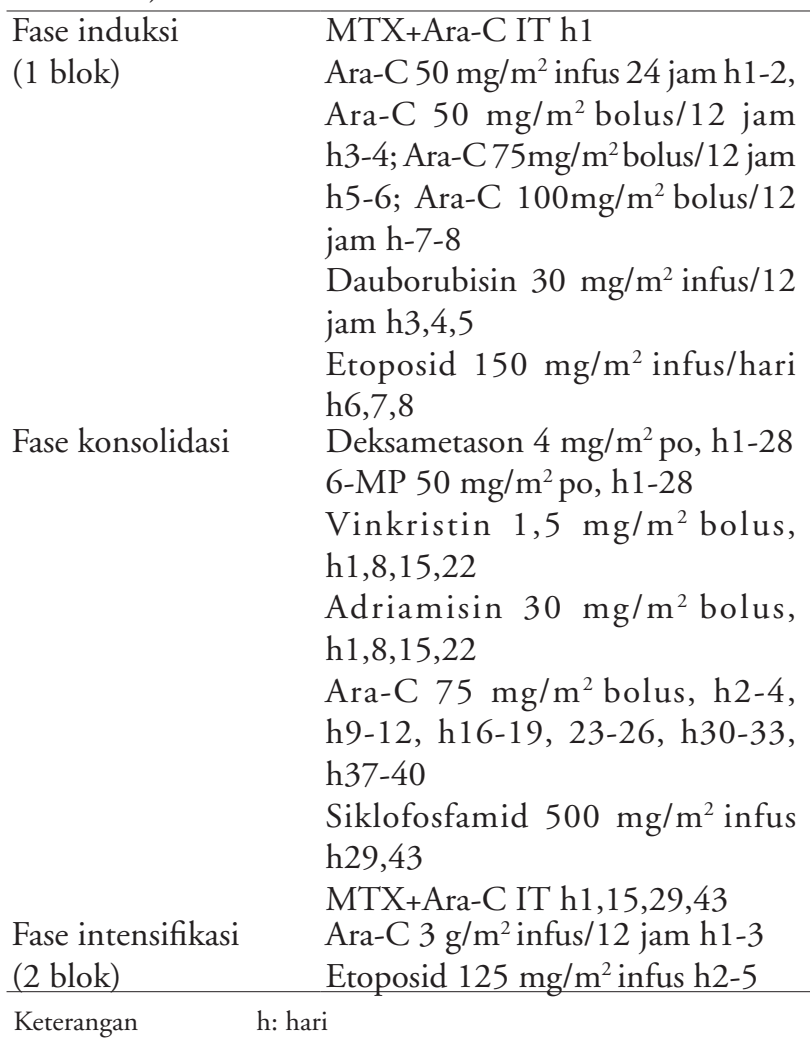


Tabel 2. Karakteristik klinis dan laboratoris

\begin{tabular}{lcccc}
\hline Variabel & Frekuensi & Kematian & Hidup & Loss to follow-up \\
\hline $\begin{array}{l}\text { Jenis kelamin } \\
\text { Laki-laki }\end{array}$ & 57 & & & \\
$\quad$ Perempuan & 36 & & & \\
Usia (tahun) & & & & \\
t & 10 & 7 & 0 & 3 \\
$>1-10$ & 61 & 31 & 5 & 25 \\
>10 & 22 & 12 & 4 & 6 \\
Klasifikasi FAB & & & & \\
M1 & 42 & 21 & 4 & 5 \\
M2 & 15 & 8 & 2 & 1 \\
M3 & 2 & 1 & 0 & 2 \\
M4 & 18 & 9 & 2 & 0 \\
M5 & 9 & 7 & 0 & 2 \\
M6 & 1 & 1 & 0 & 34 \\
M7 & 6 & 3 & 1 & \\
& & 50 & 9 & \\
\hline
\end{tabular}

Tabel 3. Hasil pengobatan

\begin{tabular}{|c|c|}
\hline Variabel & Jumlah \\
\hline \multicolumn{2}{|l|}{ Kemoterapi } \\
\hline Ya & 84 \\
\hline Tidak & 9 (6 meninggal, 3 loss to follow-up) \\
\hline Keberhasilan induksi remisi & (84 pasien) \\
\hline Remisi & 27 (13 meninggal, 7 hidup, 7 loss to follow-up) \\
\hline Tidak remisi & 57 (37 meninggal, 2 hidup, 25 loss to follow-up) \\
\hline \multicolumn{2}{|l|}{ Hepatomegali } \\
\hline Remisi & 16 \\
\hline Tidak remisi & 45 \\
\hline \multicolumn{2}{|l|}{ Luaran $(\mathrm{n}=93)$} \\
\hline Hidup & 9 \\
\hline Meninggal & 50 \\
\hline Loss to follow up & 34 \\
\hline Relaps & 12 \\
\hline Kematian & 50 (total) \\
\hline Pre-kemoterapi & 8 \\
\hline Fase induksi & 19 \\
\hline Fase konsolidasi & 17 \\
\hline Fase intensifikasi & 2 \\
\hline Pasca-kemoterapi & 4 \\
\hline OS & 46\% (IK95\% : 21\%;31\%) \\
\hline EFS & $7 \%($ IK95\% : 3\%;6\%) \\
\hline
\end{tabular}

Keterangan: $\mathrm{OS}=$ overall survival

$\mathrm{EFD}=$ event-free survival 
Sembilan subyek di antaranya tidak menjalani pengobatan kemoterapi karena menolak pengobatan, sedangkan sisanya menjalani kemoterapi menggunakan protokol LMA dari EKZ/AMC 1987 yang dimodifikasi. Subyek yang mencapai remisi atau gagal remisi tetap melanjutkan pengobatan fase konsolidasi. Subyek yang mengalami remisi pasca pengobatan kemoterapi fase induksi 27 dari 84 pasien (32\%). Angka kejadian relaps 12 dari 27 pasien, dan 2 di antaranya mengalami relaps intrakranial (isolated relapse).

Luaran pengobatan LMA menunjukkan angka kematian tinggi yaitu 54\% dan angka loss to follow-up $37 \%$. Kematian pada fase induksi dan fase konsolidasi merupakan yang tertinggi yaitu masing-masing $38 \%$ dan 34\%. Penyebab utama kematian adalah infeksi berat atau sepsis (62\%) dan perdarahan akibat trombositopenia (26\%). Empat dari 12 subyek yang mengalami relaps termasuk yang mengalami relaps intrakranial masih hidup sampai akhir pengamatan.

Kesintasan pada pasien LMA didapatkan (OS) 46\% (IK95\%: 21\%;31\%) dan EFS 6,5\% (IK95\%: $3 \% ; 6 \%$ ). Estimasi kesintasan mungkin berbeda apabila angka loss to follow-up tidak terlalu besar (Gambar 1).

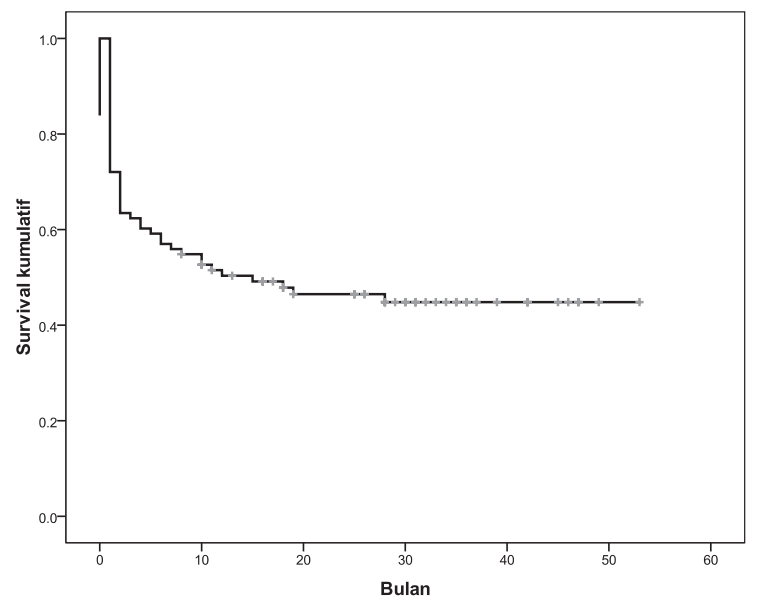

(a)

Gambar 1. Kurva kesintasan OS (a) dan EFS (b)

\section{Pembahasan}

Hasil pengobatan LMA menunjukkan luaran yang rendah apabila dibandingkan dengan laporan dari negara lain. Angka keberhasilan kemoterapi fase induksi untuk mencapai remisi $32 \%$, jauh lebih rendah dibandingkan laporan lain yang mencapai $77 \%-78 \% .^{5}$ Kardos $\mathrm{dkk}^{6}$ serta Ribeiro $\mathrm{dkk}^{7}$ menggunakan protokol kemoterapi fase induksi yang sama dengan penelitian kami dan melaporkan angka remisi 82\%. Gibson $\mathrm{dkk}^{8}$ melaporkan angka remisi yang lebih tinggi yaitu 93\% pada pasien yang menggunakan regimen kemoterapi yang sama seperti penelitian kami namun dengan dosis yang lebih tinggi dan dengan 2 blok fase induksi. Angka remisi yang tinggi (90\%) juga dilaporkan oleh Liang $\mathrm{dkk}^{9}$ dari Taiwan dengan pengobatan idarubisin, ara-C dan etoposide pada fase induksi.

Angka remisi yang rendah kemungkinan terkait dengan jenis protokol yang diberikan, faktor prognostik, dan pemberian kemoterapi yang tidak sesuai jadwal. Faktor prognostik untuk menilai kemungkinan gagal remisi pada LMA adalah pasien yang saat didiagnosis memiliki jumlah trombosit $<20.000 / \mu \mathrm{L}$, jenis kelamin laki-laki, LMA M5, hepatomegali, dan sel blast $>15 \%$ pada 14 hari pasca kemoterapi fase induksi. ${ }^{10}$ Pada penelitian kami hanya dilaporkan data tipe morfologi LMA, jenis kelamin, dan hepatomegali. Risiko relatif seorang pasien untuk mengalami gagal remisi apabila saat diagnosis terdapat hepatomegali 1,1 (IK95\% : 0,$85 ; 1,55)$. Kegagalan remisi antara pasien yang

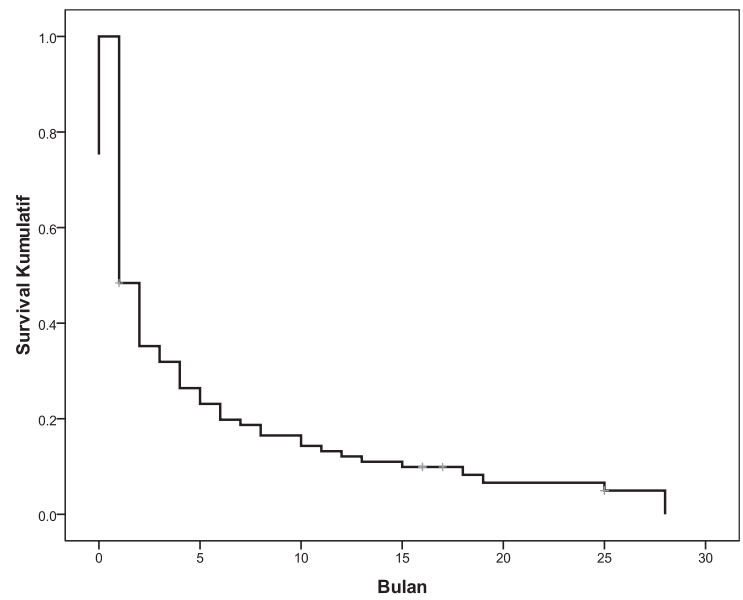

(b) terdeteksi hepatomegali dan tidak hepatomegali saat diagnosis tidak berbeda $(p>0,05)$. Hal yang sama ditemukan pada perbedaan jenis kelamin dan jumlah trombosit. Penelitian lebih lanjut perlu dilakukan untuk mengetahui faktor penyebab angka remisi yang rendah. 
Kemungkinan lain penyebab angka remisi yang rendah adalah toksisitas obat yang menyebabkan jadwal kemoterapi dimodifikasi menjadi kurang intensif. Sebagian besar pasien yang menjalani fase induksi pada umumnya mengalami aplasia berat dan menderita infeksi berat. Komplikasi infeksi banyak terjadi karena tidak adanya fasilitas ruang isolasi yang baik. Faktor lain yang diduga menyebabkan angka remisi rendah adalah ketersediaan obat kemoterapi. Sebagian besar pasien tidak mampu membeli obat sendiri atau tidak memiliki jaminan kesehatan. Sejak diberlakukan jaminan kesehatan bagi orang tidak mampu, sebagian masalah biaya dapat diatasi walaupun belum optimal.

Kesintasan pasien LMA sangat rendah terutama EFS 7\% (IK 95\%: 3,1\%;6,2\%). Perbedaan yang besar antara OS dan EFS disebabkan oleh angka loss to follow-up yang tinggi mencapai $37 \%$. Hal tersebut juga mempengaruhi estimasi kesintasan EFS. Akan tetapi perbandingan antara loss to follow-up dengan kegagalan terapi (kematian) masih kurang dari satu, sehingga estimasi kesintasan ini masih bisa dipertanggungjawabkan.

Nilai estimasi kesintasan sangat rendah apabila dibandingkan dengan laporan dari negara lain yang memakai protokol kemoterapi yang hampir sama. Berdasarkan Dutch Oncology Group Trial, Kardos dkk ${ }^{6}$ melaporkan OS $(47 \pm 6) \%$ dan EFS $(39 \pm 6) \%$ pada kelompok pasien yang mendapat protokol AML 87 seperti pada penelitian ini. Perbedaan signifikan pada EFS antara laporan tersebut dengan EFS mungkin disebabkan oleh banyak faktor, di antaranya ketersediaan obat, kesesuaian jadwal kemoterapi, perbedaan karakteristik klinis, dan pemanfaatan transplantasi sumsum tulang pada $40 \%$ subyek penelitiannya. Liang $\mathrm{dkk}^{9}$ melaporkan OS $(51 \pm 5,3) \%$ dan EFS $(50 \pm 4,8) \%$ pada pasien LMA dengan menggunakan protokol yang berbeda (idarubisin, ara-C, etoposid) dan transplantasi sumsum tulang. Gibson $\mathrm{dkk}^{8}$ melaporkan OS 65\% dan EFS 56\% pada pasien LMA yang memakai protokol kemoterapi Medical Research Council, United Kingdom (MRC) AML 12. Chan $\mathrm{dkk}^{11}$ di Malaysia menggunakan protokol BFM-AML 83 yang kurang intensif dibandingkan protokol kami melaporkan EFS 59\%. Perbedaan estimasi kesintasan mungkin dipengaruhi oleh regimen kemoterapi yang berbeda dan transplantasi yang tidak dikerjakan di RSCM. Selain itu fasilitas perawatan yang memadai juga berperan pada keberhasilan pengobatan. ${ }^{12}$
Angka kematian yang tinggi sangat berkaitan dengan kejadian infeksi berat. Protokol kemoterapi AML 87 merupakan protokol yang sangat intensif untuk LMA sehingga sangat toksik. ${ }^{7}$ Ribeiro $\mathrm{dkk}^{7}$ melaporkan angka kematian 15\% pada fase induksi akibat komplikasi infeksi pada kelompok pasien yang mendapat protokol AML 87. Angka kematian akibat infeksi hampir sama seperti laporan kami (19\%). Komplikasi infeksi mungkin dapat dicegah dengan ketersediaan fasilitas rawat yang memadai. Selain itu protokol kemoterapi yang dipakai saat ini juga perlu dievaluasi mengingat tingginya angka kejadian relaps yang tinggi dan OS rendah. ${ }^{7}$ Kejadian relaps terjadi pada 12 dari 27 subyek (44\%), seperti yang dilaporkan beberapa penelitian lain (38\%-45\%).6,7,9 Intensifikasi kemoterapi tidak serta merta menurunkan angka kejadian relaps, sehingga strategi pengobatan LMA memerlukan stratifikasi risiko, perawatan suportif yang memadai, dan penyesuaian krakteriktis pasien (sitogenetik). ${ }^{13}$

Pemakaian protokol AML 87 dilaporkan dapat mencapai angka remisi sampai $90 \%$ namun cenderung diikuti angka kejadian relaps yang tinggi dan derajat toksisitas obat yang menurunkan OS. Meskipun pasien LMA yang diterapi dengan protokol AML 87 dilanjutkan dengan transplantasi sumsum tulang, OS secara keseluruhan tetap rendah (40\%). ${ }^{7}$ Untuk mengurangi toksisitas akibat intensifikasi kemoterapi seperti pada protokol AML 87, perlu dilakukan stratifikasi risiko tiap pasien. ${ }^{7,13}$

\section{Kesimpulan}

Keberhasilan pengobatan LMA pada anak di RSCM Jakarta masih sangat rendah, terlihat pada angka remisi yang rendah, mungkin terjadi akibat beberapa faktor yang harus diteliti lebih lanjut. Kematian yang tinggi akibat infeksi berat saat fase induksi atau setelah fase induksi terjadi akibat fasilitas perawatan yang tidak memadai untuk pasien LMA yang sedang menjalani pengobatan kemoterapi. Selain itu transplantasi sumsum tulang sebagai salah satu terapi penting pada LMA, belum dapat dikerjakan di RSCM. Untuk meningkatkan keberhasilan pengobatan LMA, perlu dilakukan perbaikan protokol kemoterapi, penyediaan fasilitas perawatan yang memadai, dan seyogyanya transplantasi sumsum tulang segera dikembangkan di RSCM. 


\section{Daftar pustaka}

1. Spector LG RJ, Robison LL, Bhatia S. Epidemiology and etiology. In: Pui C-H, editor. Childhood Leukemia. Edisi Ke-2. Cambridge: Cambridge University Press; 2006.h. 48-66.

2. Data Registrasi Kanker Departemen Ilmu Kesehatan Anak FKUI/RSCM 2011.

3. Creutzig U, Ritter J, Schellong G. Identification of two risk groups in childhood acute myelogenous leukemia after therapy intensification in study AML-BFM-83 as compared with study AML-BFM-78. AML-BFM Study Group. Blood 1990 15;75:1932-40.

4. Klingebiel T, Creutzig U, Dopfer R, Ehninger G, Schmidt H, Ritter J, dkk. Bone marrow transplantation in comparison with conventional therapy in children with adult type chronic myelogenous leukemia. Bone Marrow Transplant 1990;5:317-20.

5. Smith FO, Alonzo TA, Gerbing RB, Woods WG, Arceci RJ. Long-term results of children with acute myeloid leukemia: a report of three consecutive Phase III trials by the Children's Cancer Group: CCG 251, CCG 213 and CCG 2891. Leukemia 2005;19:2054-62.

6. Kardos G, Zwaan CM, Kaspers GJ, de-Graaf SS, de Bont ES, Postma A, dkk. Treatment strategy and results in children treated on three Dutch Childhood Oncology Group acute myeloid leukemia trials. Leukemia 2005;19:2063-71.

7. Ribeiro RC, Razzouk BI, Pounds S, Hijiya N, Pui CH, Rubnitz JE. Successive clinical trials for childhood acute myeloid leukemia at St Jude Children's Research Hospital, from 1980 to 2000. Leukemia 2005;19:2125-9.

8. Gibson BE, Wheatley K, Hann IM, Stevens RF, Webb D, Hills RK, dkk. Treatment strategy and long-term results in paediatric patients treated in consecutive UK AML trials. Leukemia 2005;19:2130-8.

9. Liang DC, Chan TT, Lin KH, Lin DT, Lu MY, Chen $\mathrm{SH}$, dkk. Improved treatment results for childhood acute myeloid leukemia in Taiwan. Leukemia 2006;20:13641.

10. Wells RJ, Arthur DC, Srivastava A, Heerema NA, Le Beau M, Alonzo TA, dkk. Prognostic variables in newly diagnosed children and adolescents with acute myeloid leukemia: Children's Cancer Group Study 213. Leukemia $2002 ; 16: 601-7$.

11. Chan LL, Abdel-Latif ME, Ariffin WA, Ariffin H, Lin HP. Treating childhood acute myeloid leukaemia with the AML-BFM-83 protocol: experience in a developing country. Br J Haematol 2004;126:799-805.

12. Aledo A, Heller G, Ren L, Gardner S, Dunkel I, McKay SW, dkk. Septicemia and septic shock in pediatric patients: 140 consecutive cases on a pediatric hematology-oncology service. J Pediatr Hematol Oncol 1998;20:215-21.

13. Creutzig U, Zimmermann M, Reinhardt D, Dworzak M, Stary J, Lehrnbecher T. Early deaths and treatmentrelated mortality in children undergoing therapy for acute myeloid leukemia: analysis of the multicenter clinical trials AML-BFM 93 and AML-BFM 98. J Clin Oncol 2004;22:4384-93. 